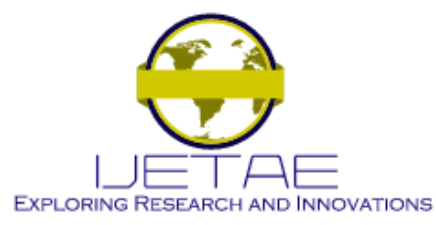

International Journal of Emerging Technology and Advanced Engineering

Website: www.ijetae.com (ISSN 2250-2459, ISO 9001:2008 Certified Journal, Volume 10, Issue 07, July 2020)

\title{
Tin Dioxide - CNT Based Gas Sensor Design
}

\author{
Sayak Mukherjee ${ }^{1}$, Anik Mukherjee ${ }^{2}$ \\ ${ }^{1}$ University of Calcutta \\ ${ }^{2}$ Camellia Institute of Technology
}

\begin{abstract}
The $\mathrm{SnO}_{2}$-CNT based gas sensors can detect harmful gases and also measure their toxic effects on environment as well as living creatures. Monitoring of the sensitivity of the hazardous gases (CO) and volatile organic compound (Acetone) by our $\mathrm{SnO}_{2}$-CNT based gas sensor are the main goal here. Cross sensitivity of $\mathrm{SnO}_{2}$-CNT based gas sensor over volatile organic compound (ethyl alcohol) and combustible gases (methane) are also observed here.
\end{abstract}

Keywords- $\mathrm{SnO}_{2}$-CNT gas sensors, sensitivity of gas sensors, capacitive effect, Scanning Electron Microscopy (SEM), High energy Sonicator, substrate coating and X-ray diffraction (XRD).

\section{INTRODUCTION}

Nowadays $\mathrm{SnO}_{2}$ gas sensors are extensively used in research and development for its higher sensitivity which is mainly based on the high operating temperature. These ntype semi-conductive gas sensor is first introduced in 1962 from then a wide range of toxic gases are monitoring through it. Tin dioxide $\left(\mathrm{SnO}_{2}\right)$ is an anisotropic polar crystalline material with tetragonal rutile lattice structure also it shows various properties in bulk and nano dimensions, this oxide materials shows several physical and chemical properties. Tin dioxide obeys to the $\mathrm{O}=\mathrm{Sn}=\mathrm{O}$ structure, among all the elements of Group-IV of the periodic table $\mathrm{SnO}_{2}$ is always preferable for its conductivity, transparency and particle size. The conductivity of Tin dioxide $\left(\mathrm{SnO}_{2}\right)$ is realised by oxygen vacancies, concentration of oxygen vacancies is very difficult to control. Changing the electrical resistance senses the toxic gases. Electrical resistances is depends upon various surface phenomena alike surface impurities, doping concentration, composition of elements and so on. The lattice parameters are $\mathrm{a}=4.737 \AA$ and $\mathrm{c}=3.185 \AA$ when $a=b$, subsequently the ratio of $c / a$ is 0 . 673.It is basically $6: 3$ coordination lattice structure. The band gap of $\mathrm{SnO}_{2}$ is $3.6 \mathrm{eV}$, besides that conductivity of the sensor decreases in the presence of oxidizing gases alike $\mathrm{O}_{2}$ and rises for the reducing gases like $\mathrm{CO}$. The relationship between the gas concentrations with the resistance of $\mathrm{SnO}_{2}$ is non-linear since resistance of $\mathrm{SnO}_{2}$ varying always due to variation of the concentration of gas. Performance of a gas sensor depends on its sensitivity, response time, selectivity and chip size.
The size of Tin dioxide particles are in nanometre range so using $\mathrm{SnO}_{2}$ in gas sensors are reducing the size of sensing device as well as nanocomposite materials are also made with $\mathrm{SnO}_{2}$ by adding the dopants. The performance of the gas sensor also depends on its selectivity, if it is low then SNR (Signal to Noise Ratio) will be lowered and the targeted gas cannot be sense properly by that sensing device. $\mathrm{SnO}_{2}$ gas sensors are known for its high sensitivity and low response time because of particle size of this sensing material and operating temperature. The operating temperature is another important parameter, at low temperature when the target gases are introduced the sensor response is insignificant as oxygen is lowered. $\mathrm{SnO}_{2}$ sensors shows maximum sensing response depends on their operating temperature, up to the critical temperature the sensing responses of Tin dioxide sensors are increases but above that responses will fall again. It is basically depending on absorption and desorption rates of sensors. The range of working temperature is between $25^{\circ} \mathrm{C}-500^{\circ} \mathrm{C}$ for Tin dioxide sensors..

\section{FABRicAtion OF THE SENSOR}

To prepare $\mathrm{SnO}_{2}$, at first, $0.2 \mathrm{M} \mathrm{SnCl} 4.5 \mathrm{H}_{2} \mathrm{O}(100 \mathrm{~mL})$ aqueous solution was prepared by adding distilled water by high energy sonication. After that, for making a clear solution 2-3 mL of HCL was added by a dropper, then $\mathrm{NH}_{3}$ solution was slowly added with it until a white precipitate was obtained. This procedure was continued for 1 hour with high sonication. Finally, the precipitate was washed with distilled water 2-3 times and acetone then collected. The cleaned precipitate powder was dried at $100^{\circ} \mathrm{C}$ vacuum chamber for $12 \mathrm{~h}$ to eliminate volatile compounds.

Next to cover $\mathrm{SnO}_{2}$ with $\mathrm{CNT}$, first high energy Sonication of CTAB (cetyl trimethyl ammonium bromide) and CNT (Carbon Nanotube) was done for 25-30 min with distilled water, where the ratio of CTAB and CNT were 5:1. $\mathrm{SnO}_{2}$ powder previsously mixed with $\mathrm{CNT}$ sol and heating $50-60^{\circ} \mathrm{C}$ also stirring it to make a thick paste. Then Al was coated by the paste. Different composition samples alike $\mathrm{SnO}_{2}+.75 \mathrm{wt} \% \mathrm{CNT}, \mathrm{SnO}_{2}+0.25$ wt $\% \mathrm{CNT}, \mathrm{SnO}_{2}$ $+2 \mathrm{wt} \% \mathrm{CNT}, \mathrm{SnO}_{2}+1 \mathrm{wt} \%, \mathrm{SnO}_{2}+1.5 \mathrm{wt} \%, \mathrm{SnO}_{2}+0.5$ $\mathrm{wt} \%$ were then prepared. Al coated substrates then cut into specific dimensions $3.5 \mathrm{~mm} \times 2 \mathrm{~mm} \times 0.5 \mathrm{~mm}$ (approx.) for measurement and polished. 


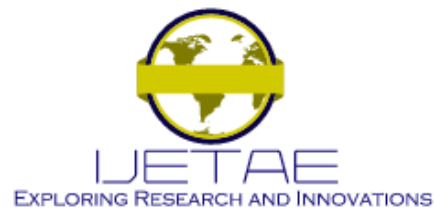

International Journal of Emerging Technology and Advanced Engineering

Website: www.ijetae.com (ISSN 2250-2459, ISO 9001:2008 Certified Journal, Volume 10, Issue 07, July 2020)

After cleaning the tubes with HCL, distilled water and acetone, finally $\mathrm{Au}$ electrode and platinum lead wires were attached with $\mathrm{Al}$ substrate. Gold coated Al substrate was cured at $950^{\circ} \mathrm{C}$ for $1 \mathrm{~h}$.

To prepare the sensor, aluminum substrate was sliced and polished into length $\sim 3.5 \mathrm{~mm}$, outer diameter $\sim 2 \mathrm{~mm}$, and thickness $\sim 0.5 \mathrm{~mm}$ and both the edges of the tube and subsequently cleaned with $\mathrm{HCl}$, DI water, IPA and acetone. Then on the aluminum substrates we connected $\mathrm{Au}$ and $\mathrm{Pt}$ electrode and wires. Next, the sensing powders $\left(\mathrm{SnO}_{2} /\right.$ $\mathrm{SnO}_{2}+\mathrm{CNT}$ ) and slight IPA (isopropyl alcohol) were mixed for making thick pastes. These pastes were then coated over substrates (thickness of the coatings was about $50 \mu \mathrm{m}-60 \mu \mathrm{m})$. Finally, coated substrate was cured at $350^{\circ} \mathrm{C}$ for $1 \mathrm{~h}$. Now, both contacts were spot welded by $\mathrm{Ni}$ pins fixed on sensor head and inside the tube nichrome heating coil were successfully placed. For monitoring the change in resistivity of the sensing materials two pins of the packaged sensors were connected with a multimeter. For controlling the voltage change the other pins were connected with a dc power supply. Preferably sensors were placed in a closed glass jar, vaporous /liquid gases were finally injected into the closed jar by a syringe.

\section{Measurement And Characterization Of The GAS} SENSOR

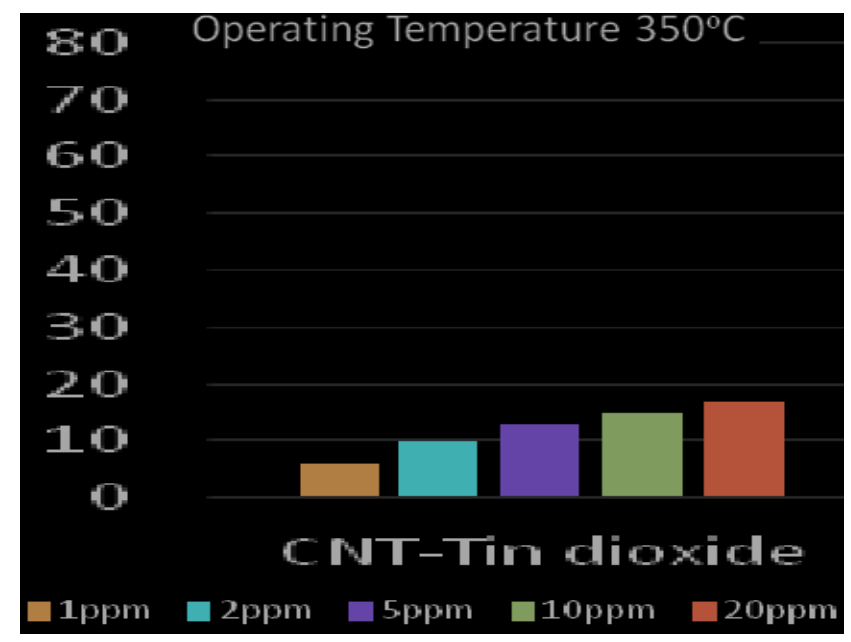

Figure 1 Sensors response to acetone vapor
Here Tin dioxide is used as a semiconducting matrix or a dielectric material and CNT is used as a conductive filter. $\epsilon_{\text {eff }}$ is symbolically represented the effective dielectric constant, which is defined as,

$$
\epsilon_{\text {eff }}=\epsilon_{\mathrm{m}}\left(\left(\mathrm{p}_{\mathrm{c}}-\mathrm{p}\right) / \mathrm{p}_{\mathrm{c}}\right)^{-\mathrm{q}}
$$

Where, ${ }^{\mathrm{Pc}}=$ percolation threshold (The value of $\mathrm{Pc}$ is approx. 0.16 for 3-D lattice structure)

$\mathrm{P}=$ Volume concentration

$\epsilon_{\mathrm{m}}=$ Dielectric constant of the semiconductor matrix

The value of $\mathrm{q}$ is approximately 0.9 for threedimensional lattice structure

At the percolation threshold the effective dielectric constant increases sharply, this is happed due to separation of metallic filter by semiconducting materials. The depletion region of Tin dioxide semiconductor producing a capacitive effect on conducting CNT's. For detecting the acetone vapor the depletion layer width is being reduced and overall capacitive effect also decreased. For gas absorption heterojunction $\mathrm{SnO}_{2}$-CNT metal-semiconductor sensor are being used, by changing the depletion region the barrier height can be controlled.

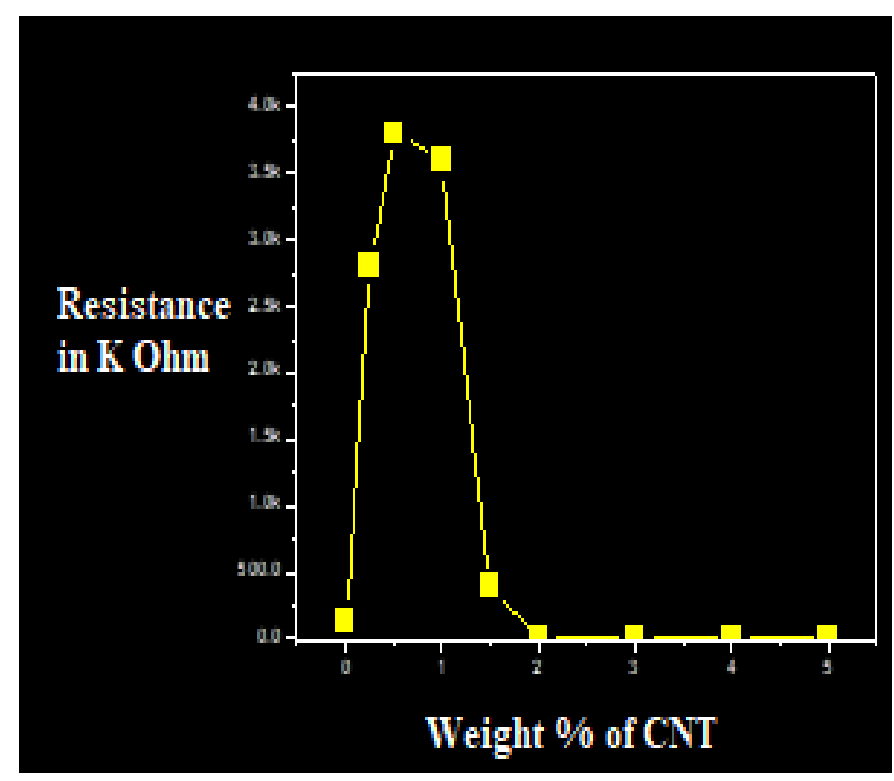

Figure 2 Amount of CNT vs resistance of the sensor 


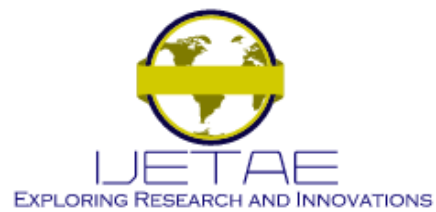

International Journal of Emerging Technology and Advanced Engineering Website: www.ijetae.com (ISSN 2250-2459, ISO 9001:2008 Certified Journal, Volume 10, Issue 07, July 2020)

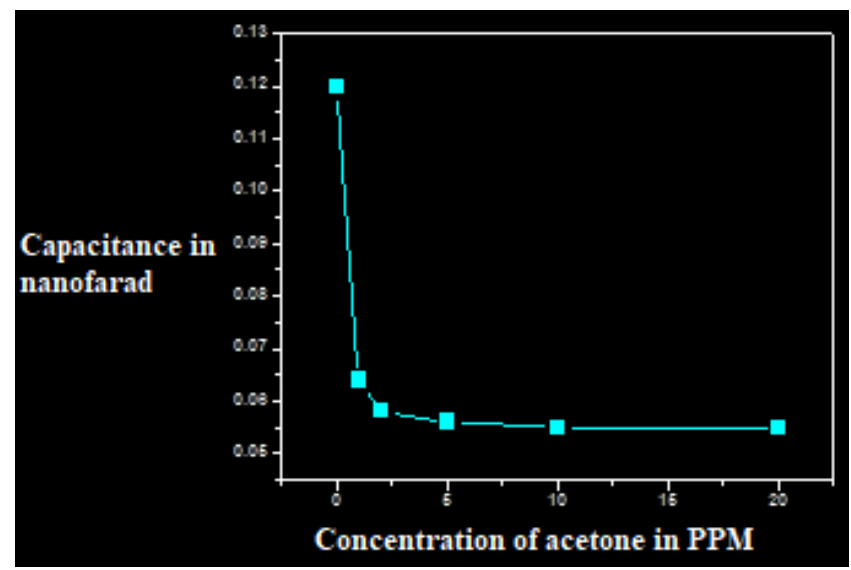

Figure 3 Acetone concentration vs capacitance change

\section{CONCLUSION}

In this research work the sensitivity of $\mathrm{CO}$ and acetone are successfully observe by fabricated $\mathrm{SnO}_{2}-\mathrm{CNT}$ based gas sensor. Different types of Tin dioxide-based sensors can be fabricated using this technique and used in various sensing devices. The capacitive effect of $\mathrm{SnO}_{2}-\mathrm{CNT}$ contacts provides no effect on carbon monoxide, moisture, methane and alcohol vapor. Further study is required to innovate the reason behind the phenomena.

\section{REFERENCES}

[1] Basu, Srismrita, Hsuan-Chao Hou, Debsmita Biswas, Subhodip Maulik, Theda Daniels-Race, Mandi Lopez, Michael Mathis, and Martin Feldman. "A needle probe to detect surface enhanced Raman scattering (SERS) within solid specimen." Review of Scientific Instruments 88, no. 2 (2017): 023107.

[2] Basu, Srismrita, Subhodip Maulik, Hsuan-Chao Hou, Theda Daniels-Race, and Martin Feldman. "Surface enhanced Raman spectroscopic substrate utilizing gold nanoparticles on carbon nanotubes." Journal of Applied Physics 122, no. 17 (2017): 175107.

[3] Mazumdar, J., M. Chawla-Sarkar, K. Rajendran, A. Ganguly, U. K. Sarkar, S. Ghosh, M. D. Sarkar, and S. Maulik. "Burden of respiratory tract infections among paediatric in and out-patient units during 2010-11." Eur Rev Med Pharmacol Sci 17, no. 6 (2013): 802 8 .

[4] Maulik, Subhodip, Anirban Sarkar, Srismrita Basu, and Theda Daniels-Race. "Voltage-Controlled Spray Deposition of Multiwalled Carbon Nanotubes on Semiconducting and Insulating Substrates." Journal of Electronic Materials 47, no. 8 (2018): 4604 4609.

[5] Maulik, Subhodip, Srismrita Basu, Hsuan-Chao Hou, and Theda Daniels-Race. "Voltage-Controlled Deposition of Dispersed Carbon Nanotubes onto a Conducting Substrate Without a Catalyst." Advanced Science, Engineering and Medicine 10, no. 6 (2018): 564-567.
[6] Hou, Hsuan-Chao, Yaser Mohammadi Banadaki, Srismrita Basu, Subhodip Maulik, Shu-Wei Yang, Safura Sharifi, Martin Feldman et al. "Characterization of Sputtered Nano-Au Layer Deposition on Silicon Wafer." International Journal of Advanced Research Trends in Engineering and Technology 3, no. 12 (2017).

[7] Maulik, Subhodip, Srismrita Basu, and Theda Daniels-Race. "Electrospray-assisted carbon nano tube deposition on aluminum without a binding agent." Bulletin of the American Physical Society 61 (2016).

[8] Maulik, Subhodip. "Realization of low cost bluetooth based visual sensor node for pest and disease detection in crops." International Journal of Emerging Technology and Advanced Engineering 2, no. 6 (2012).

[9] Kumari, R., S. C. Manchanda, and S. L. Maulik. "Effect of pre-and posttreatment of losartan in feline model of myocardial ischemicreperfusion injury." Methods and findings in experimental and clinical pharmacology 26, no. 1 (2004): 39-46.

[10] Maulik, Subhodip, Srismrita Basu, and Theda Daniels-Race. "Dispersed Molybdenum Disulfide Deposition onto a Conducting Substrate Using a Voltage Controlled Deposition Technique." Advanced Science, Engineering and Medicine 10, no. 12 (2018): 1224-1226.

[11] Maulik, S., Basu, S., Kanakamedala, K. and Daniels-Race, T., 2019. A Review of Atomic Scale Characterization Techniques of Molybdenum Disulfide (MoS 2). Journal of Electronic Materials, 48(6), pp.3451-3458.

[12] Maulik, Subhodip. "Voltage-Controlled Deposition of Nanoparticles for Next Generation Electronic Materials." (2018).

[13] Samanta, Sayan, Subhodip Maulik, and Srismrita Basu. "Development of Temperature Monitoring and Control System Using Temperature Sensor." IJERT 1, no. 8 (2012): 1-8.

[14] Basu, Srismrita, Sayani Sarkar, and Subhodip Maulik. "An Energy Efficient Algorithmic Rule for Audio Compression of Wireless Sensor Networks (WSNs)."

[15] Maulik, Subhodip, Sayani Sarkar, and Srismrita Basu. "Relative Study of Power and Delay in 8X8 Precision Multipliers."

[16] Basu, Srismrita, and Subhodip Maulik. "Realization of MIN-MAX Circuit for Rule Base Block of Fuzzy Logic Temperature Controller using P-Spice Simulator."

[17] Basu, Srismrita. "Realization of fuzzy logic temperature controller." International Journal of Emerging Technology and Advanced Engineering 2, no. 6 (2012).

[18] Basu, Srismrita, HsuanChao Hou, Debsmita Biswas, Theda DanielsRace, Mandi Lopez, J. Michael Mathis, and Martin Feldman. "Single fiber surface enhanced Raman scattering probe." Journal of Vacuum Science \& Technology B, Nanotechnology and Microelectronics: Materials, Processing, Measurement, and Phenomena 35, no. 6 (2017): 06GF01.

[19] Hou, Hsuan-Chao, Yaser M. Banadaki, Srismrita Basu, and Safura Sharifi. "A Cost-Efficient Surface Enhanced Raman Spectroscopy (SERS) Molecular Detection Technique for Clinical Applications." Journal of Electronic Materials 47, no. 9 (2018): 5378-5385.

[20] Basu, Srismrita. "Surface Enhanced Raman Scattering (SERS) Substrates and Probes." (2017). 


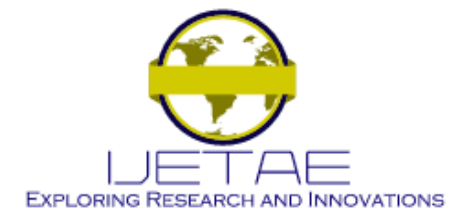

\section{International Journal of Emerging Technology and Advanced Engineering Website: www.ijetae.com (ISSN 2250-2459, ISO 9001:2008 Certified Journal, Volume 10, Issue 07, July 2020)}

[21] Kanakamedala, Kalyan, Jared DeSoto, Anirban Sarkar, and Theda Daniels Race. "Study of electrospray assisted electrophoretic deposition of carbon nanotubes on insulator substrates." Electronic Materials Letters 11, no. 6 (2015): 949-956.

[22] Sarkar, Anirban, Kalyan Kanakamedala, Naveen N. Jagadish, Atiya Jordan, Susmita Das, Noureen Siraj, Isiah M. Warner, and Theda Daniels-Race. "Electro-optical characterization of cyanine-based GUMBOS and nanoGUMBOS." Electronic Materials Letters 10, no. 5 (2014): 879-885.

[23] Sarkar, A., K. Kanakamedala, M. D. Rajathadripura, N. N. Jagadish, P. K. S. Magut, S. de Rooy, S. Das, B. El-Zahab, I. M. Warner, and T. Daniels-Race. "Electro-optical characterization of nanoGUMBOS." Electronic Materials Letters 10, no. 4 (2014): 775 781.

[24] Siraj, Noureen, Susmita Das, Farhana Hasan, Kalyan Kanakamedala, Theda Daniels-Race, and Isiah M. Warner. "Evaluation of thin films based on fluorescent and conductive GUMBOS." In ABSTRACTS OF PAPERS OF THE AMERICAN CHEMICAL SOCIETY, vol. 245. 1155 16TH ST, NW, WASHINGTON, DC 20036 USA: AMER CHEMICAL SOC, 2013.

[25] Kanakamedala, Kalyan, and Theda Daniels-Race. "Alternative Method of Electrospraying for Scalable Deposition of Nanomaterials." Bulletin of the American Physical Society 59 (2014).

[26] Kanakamedala, Kalyan, Noureen Siraj, Madhavi Divakar, Farhana Hasan, Susmita Das, Isiah Warner, and Theda Daniels-Race. "Morphology and conductivity studies on carbazole based GUMBOS thin films." Bulletin of the American Physical Society 57 (2012).

[27] Kanakamedala, Kalyan, Sergio De Rooy, Susmita Das, Bilal ElZahab, Isiah Warner, and Theda Daniels-Race. "Determination of the Current Voltage Signatures of NanoGUMBOS." In APS Southeastern Section Meeting Abstracts. 2011.

[28] Kanakamedala, Kalyan Chakravarthy. "Hybrid Electronic Materials: Characterization and Thin-film Deposition." (2015).

[29] Kanakamedala, Kalyan. "Characterization of Tin-Oxide (SnO2-Ni) Based Sensors."

[30] Kanakamedala, Kalyan. "Fabrication and Analysis of Tin Oxide-Ni (SnO2-Ni) Sensors."

[31] Chatterjee, Shre Kumar, Saptarshi Das, Koushik Maharatna, Elisa Masi, Luisa Santopolo, Stefano Mancuso, and Andrea Vitaletti. "Exploring strategies for classification of external stimuli using statistical features of the plant electrical response." Journal of the Royal Society Interface 12, no. 104 (2015): 20141225.
[32] Chatterjee, Shre Kumar, Sanmitra Ghosh, Saptarshi Das, Veronica Manzella, Andrea Vitaletti, Elisa Masi, Luisa Santopolo, Stefano Mancuso, and Koushik Maharatna. "Forward and inverse modelling approaches for prediction of light stimulus from electrophysiological response in plants." Measurement 53 (2014): 101-116.

[33] Das, Saptarshi, Barry Juans Ajiwibawa, Shre Kumar Chatterjee, Sanmitra Ghosh, Koushik Maharatna, Srinandan Dasmahapatra, Andrea Vitaletti, Elisa Masi, and Stefano Mancuso. "Drift removal in plant electrical signals via IIR filtering using wavelet energy." Computers and Electronics in Agriculture 118 (2015): 15-23.

[34] Chatterjee, Shre Kumar, Saptarshi Das, Koushik Maharatna, Elisa Masi, Luisa Santopolo, Ilaria Colzi, Stefano Mancuso, and Andrea Vitaletti. "Comparison of decision tree based classification strategies to detect external chemical stimuli from raw and filtered plant electrical response." Sensors and Actuators B: Chemical 249 (2017): 278-295.

[35] Snow, Stephen, Anna Soska, Shre Kumar Chatterjee, and M. C. Schraefel. "Keep Calm and Carry On: Exploring the Social Determinants of Indoor Environment Quality." In Proceedings of the 2016 CHI Conference Extended Abstracts on Human Factors in Computing Systems, pp. 1476-1482. 2016.

[36] Chatterjee, Shre Kumar, Obaid Malik, and Siddharth Gupta. "Chemical sensing employing plant electrical signal responseclassification of stimuli using curve fitting coefficients as features." Biosensors 8, no. 3 (2018): 83.

[37] Biswas, Dwaipayan, Valentina Bono, Michael Scott-South, Shre Chatterjee, Anna Soska, Steve Snow, Catherine Noakes, Janet F. Barlow, Koushik Maharatna, and M. C. Schraefel. "Analysing wireless EEG based functional connectivity measures with respect to change in environmental factors." In 2016 IEEE-EMBS International Conference on Biomedical and Health Informatics (BHI), pp. 599602. IEEE, 2016.

[38] Chatterjee, Shre. "An approach towards plant electrical signal based external stimuli monitoring system." $\mathrm{PhD}$ diss., University of Southampton, 2017.

[39] Chatterjee, Shre. "An approach towards plant electrical signal based external stimuli monitoring system." PhD diss., University of Southampton, 2017.

[40] Snow, Stephen, Hannah Gough, Shre Chatterjee, and Anna Soska. "Exploring the influence of social factors on indoor environment quality." Indoor Air (2016): 1-8. 